Portland State University

PDXScholar

$5-24-2017$

\title{
Supervisor Self-Other Agreement, Family-Supportive Supervisor Behaviors and Job Attitudes
}

Luke D. Mahoney

Follow this and additional works at: https://pdxscholar.library.pdx.edu/honorstheses

Let us know how access to this document benefits you.

\section{Recommended Citation}

Mahoney, Luke D., "Supervisor Self-Other Agreement, Family-Supportive Supervisor Behaviors and Job Attitudes" (2017). University Honors Theses. Paper 385.

https://doi.org/10.15760/honors.380

This Thesis is brought to you for free and open access. It has been accepted for inclusion in University Honors Theses by an authorized administrator of PDXScholar. Please contact us if we can make this document more accessible: pdxscholar@pdx.edu. 
Running Head: Supervisor Self-Other Agreement

Supervisor Self-Other Agreement, Family-Supportive Supervisor Behaviors and Job Attitudes

by

Luke D. Mahoney

An undergraduate honors thesis submitted in partial fulfillment

of the requirements for the degree of

Bachelor of Arts

in

University Honors

and

Psychology

Thesis Adviser

Dr. Leslie B. Hammer

Portland State University 


\begin{abstract}
This paper joins the literature on family-supportive supervisor behavior research and the self-other agreement (SOA) paradigm to ask the question, how does a congruent perspective in the supervisor-employee dyad relate to service-member workplace attitudes and work-family relationships? Supervisors rated themselves on Family-Supportive Supervisor Behaviors (FSSB) and were in turn rated by their service-member employees. Results of a polynomial regression and surface-response analysis point to the conclusion that as supervisor and service-members' ratings of the supervisors FSSB rise in tandem, self-reported service-member workplace outcomes (job satisfaction, organizational commitment) rose as well. The variance in work-tofamily conflict and work-to-family enrichment was not captured to a large enough extent by the SOA model to support the surface-response analysis. Contained within are further results and a discussion about the importance of congruence between both perspectives.
\end{abstract}




\section{Introduction}

What is commonly considered good workplace supervision is changing. Empirical evidence of the importance of family-supportive supervisor behaviors in organizational settings continues to emerge. The training and development of sound supervisory practices (leadership development) continues to evolve. A valuable tool in developing leaders is the feedback provided by other employees (Day, Fleenor, Atwater, Sturm, \& McKee, 2014). Assessments looking at various meaningful leadership behaviors are often conducted to assist with motivating the behavioral change that leads to beneficial organizational outcomes. Specifically, multisource performance assessments are frequently used to foster leadership development within organizations and have become the focus of a dedicated field of research within the management literature (Day et al., 2014). A review of the literature shows that SOA impacts many important organizational outcomes including leadership performance, job satisfaction and organizational commitment (Fleenor, Smither, Atwater, Braddy, \& Sturm, 2010). However, SOA research has yet to look at the effects of rating congruence on health and family-related outcomes.

The primary purpose of this study is to examine the effects of SOA on work-family conflict (WTFC) and work-family enrichment (WTFE) outcomes using the FSSB measure which targets family-centric behaviors. The relationship between rating congruence and work-family dynamics has the possibility to identify those who might be in the greatest need for an intervention targeting work-family supportive behaviors. At the same time, organizational variables of interest (e.g. affective organizational commitment and job satisfaction) are evaluated as important outcome variables because of their relevance to the experience of work for all employees and their precedence in the literature (Bakker \& Schaufeli, 2008). 
Family-Supportive Supervisor Behaviors. The first decade of the $21^{\text {st }}$ century saw a burgeoning convergence of public opinion, research and policy change regarding the interface between work and family life (Bianchi \& Milkie, 2010). A survey of 1,051 employers in 2014 revealed that the retention of employees, and help with the management of work and family life, were the top two reasons for implementing employee and family assistance programs (Matos \& Galinsky, 2014). Moreover, 28\% of working adults in the U.S. surveyed in 2016 reported having to care for an ill, injured or disabled family member (NPR, Robert W. Johnson Foundation, Harvard School of Public Health, 2016). In recognition of the prevalence of work-family demands on workers, Hammer, Kossek, Yragui, Bodner and Hanson (2009) developed a survey designed to assess the relationship between family-supportive supervisor behaviors (FSSB) and important organizational outcomes. Hammer, Kossek, Bodner and Crain (2013) defined FSSB as “behaviors exhibited by supervisors that are supportive of employees' family roles." In the development of the FSSB measure, Hammer et al., (2009) found that employee perceptions of FSSB in the workplace were negatively related to work-family conflict and turnover intentions and positively related to job satisfaction and family-work positive spillover. These relationships went above and beyond the variation in these outcome variables accounted for by general supervisor support. In a sample of grocery store employees, Hammer, Kossek, Anger, Bodner and Zimmerman (2011) found that increasing FSSB in the workplace via a supervisor training intervention was positively related to 1) job satisfaction and 2) negatively related to turnover intentions at time 2, for those with high baseline family-work conflict. More recently, Matthews, Mills, Trout and English (2014) found FSSB to be positively related to work-engagement above a measure of perceived managerial effectiveness and that work-engagement mediated the relationship between FSSB and subjective well-being. Importantly, they also found that even 
employees without dependents at home felt benefitted from family-supportive workplace policies as measured by engagement and subjective well-being (Matthews et al., 2014). Even more recent research shows substantive relationships between improvements in employee perceptions of FSSB following a supervisor intervention and employee reports of job satisfaction and organizational commitment (Odle-Dusseau, Hammer, Crain, \& Bodner, 2016). Furthermore, family-supportive supervisor behaviors are thought of as job resources. Bakker, Hakanen, Demerouti and Despoina (2007) demonstrated that job resources (e.g. supervisor support) boost job engagement. Family-supportive policies and supervisor support are workplace resources that drive key job attitudes. These studies combined provide a theoretical and practical foundation for considering the FSSB construct as a critical component of leadership behavior. Thus, the following hypothesis was proposed:

Hypothesis 1. Service member reported FSSB will be positively related to a) job satisfaction, b) affective organizational commitment, c) work-to-family enrichment and d) negatively related to work-to-family conflict.

Self-Other Agreement. SOA is the congruence or agreement between self-reported ratings and other-reported ratings and often is a considered a proxy for self-awareness (Fleenor, McCauley, \& Brutus, 1996; Fleenor et al., 2010). According to Atwater and Yammarino (1997), research designs analyzing both self and other reports possess incremental validity over self or other-reported metrics alone. Moreover, research shows that the congruence between the supervisors and their direct reports is more important than congruence with peers or supervisors (Halverson, Tonidandel, Barlow, \& Dipboye, 2002). The reason supervisor feedback increasingly utilizes multiple sources of feedback is due to the recognition that self-ratings often lack validity in organizational settings due to halo and leniency biases (Fox, Caspy, \& Reisler, 
1994). Moreover, researchers recognize that there is often a significant discrepancy between supervisor's self-ratings and the ratings of others such as peers or direct reports (Harris \& Schaubroeck, 1988; Tsui \& Ohlott, 1988). This phenomenon has been scrutinized in the management literature, and as a result, the concept of self-other agreement (SOA) emerged over three decades ago.

As of 2010, few studies had examined the relationship between SOA and employee outcomes, as most research is focused on supervisor outcomes such as leadership performance and promotion (Fleenor et al., 2010). However, one study conducted by Szell and Henderson (1997) found that rating congruence on measures of performance and motivation was positively related to employee job satisfaction and organizational commitment. More recently, one study utilized the SOA research paradigm to assess congruence on measures of leadership authenticity and employee outcomes and found congruence significantly related to job satisfaction (Černe, Dimovski, Marič, Penger, \& Škerlavaj, 2014).

Hypothesis 2. Congruence between self (supervisor) and other (service member) reports of FSSB will be positively related to a) job satisfaction, b) affective organizational commitment, c) work-to-family enrichment and d) negatively related to work-to-family conflict.

\section{Methods}

Participants. The data come from a study of veterans and service members (National Guard) who are employed in civilian workplaces. Participants (both service members and civilian supervisors) were recruited as part of a workplace intervention study aimed at training civilian supervisors to be more receptive and supportive of veterans in the workplace. For this 
study the term "service-member" is used to denote any person who had previously served while on Active Duty in the U.S Armed Forces, the Reserves, or the National Guard as well as any person currently serving in any of the Reserve Components or the National Guard. To be eligible to participate in the study, service member participants needed to: 1) currently work for a participating organization at least 20 hours a week and 2) have served in the U.S. military in any branch during the period December 31, 2001, to the beginning of the study. The post-9/11/2001 restriction was due to the focus of this study being on service-member reintegration into the workplace.

Potential participants were identified by recruiting organizations in the Pacific Northwest. Organizations were identified through personal and professional contacts, attending veteran job fairs and other similar events, partnering with other organizations to recruit on our behalf, as well as targeting organizations and industries known to have a high proportion of service members (e.g., first responders, security firms). We also recruited at local Chambers of Commerce meetings and other employer organizations. Once an organization was recruited, veterans and supervisors were invited to participate. Once they self-identified and met the study criteria, service members received surveys via email. Service member employees completed their survey during non-workhours and received a $\$ 25$ gift card for the completion of each survey. Supervisors were not compensated and could complete the surveys during work time.

Demographics. The mean age of supervisors in this linked sample was 50 years old ( $S D$ $=8.2)$, most were married $(72 \%)$, they were primarily white $(89 \%)$ and most were male $(69 \%)$. They had spent an average of 16 years at their organization $(S D=8.6)$. The average age of the service members in this linked sample was 40 years old $(S D=9.13)$, most were married $(68 \%)$, 
and they were primarily white (90\%). $72 \%$ had children, but a majority (60\%) had two or more children. Most were male (84\%).

Response rates. Of the 42 organizations who agreed to participate, six did not have eligible veterans for participation, and one organization did not have supervisors who signed up to complete the training leaving a total of 35 . A total recruitment pool of 79,550 employees was established based on the total number of employees working in the participating organizations with 1,847 completing the pre-screener survey ( $2.3 \%$ of the employee pool). Of those, 614 (33.2\% of those completing the pre-screener) met the service member eligibility criteria (i.e. service post-9/11 and > 20 hours/week). Service member participants returned 535 surveys, but after checking for consent and completeness, only 505 surveys were considered for final analysis.

Linking. Not all supervisors and service member were linked, or both completed surveys in tandem. Some of the participating service members did not have participating supervisors. Thus, of the entire sample of service members and supervisors, 96 supervisor-service member links existed where the FSSB measure was completed by both supervisor and their service member employee. Because service member variables were the outcomes of interest, supervisor self-reported FSSB was matched to the service member. Therefore, each service member employee had a corresponding supervisor for this study. Once the supervisor to service-member links were established only 13 organizations of the original 35 remained represented in the sample.

Measures. FSSB is a self or other-report measure of behaviors exhibited by supervisors who support employees' family roles and consists of four underlying behavioral dimensions (emotional support, role modeling, instrumental support, creative/win-win management; 
Hammer, Kossek, Bodner, \& Crain, 2013). Items were rated from 1 (strongly disagree) to 5 (strongly agree). An example item is, "My supervisor makes me feel comfortable talking with him/her about my conflicts between work and non-work." Supervisors were asked to report their own FSSBsu (self; $\alpha=.66$ ), and service-members were asked to report their supervisors FSSBsm (other; $\alpha=.90$ ). These measures combined provide the self-other perspective which is the focus of this study. Each was centered on zero. Table 1 contains descriptive statistics.

Job satisfaction $(\mathbf{J S})$ was measured using the scale $(\alpha=.86)$ developed by Hackman and Oldham (as cited in Seashore, Lawler, Mirvis, \& Cammann, 1983). Items were rated from 1 (strongly disagree) to 5 (strongly agree). An example item from this scale is "In general, you like working at your job." Organizational commitment (OC) was measured on a four-item scale $(\alpha=.94)$ developed by Meyer, Allen and Smith (1993). Items were rated from 1 (strongly disagree) to 5 (strongly agree). An example item from this scale includes "I feel a strong sense of "belonging" to my organization." Work-to-family conflict (WTFC) was measured using a short-form metric ( $\alpha=.74)$ devised by Matthews, Kath and Barnes-Farrell (2010) to capture the full nature of the multi-dimensional WTFC construct (time-based, strain-based and behaviorbased pressures) in an abbreviated way. Items were rated from 1 (strongly disagree) to 5 (strongly agree). An example item on this measure is "I have to miss family activities due to the amount of time I must spend on work responsibilities.” Work-to-family enrichment (WTFE) was measured using a scale $(\alpha=.91)$ designed to capture the positive aspect of the work-family interface (Carlson, Kacmar, Wayne, \& Grzywacz, 2006). Items were rated from 1 (strongly disagree) to 5 (strongly agree). An example item is "My work helps me to understand diff erent viewpoints and this helps me be a better family member." See Table 1 for descriptive statistics. 


\section{Results}

Correlations between FSSBsm and JS $(\mathrm{r}(96)=.30, p<.05), \mathrm{OC}(\mathrm{r}(96)=.38, p<.05)$ and WTFE $(\mathrm{r}(96)=.23, p<.05)$ were all positive and significant, supporting hypotheses $1 \mathrm{a}-\mathrm{c}$. However, the correlation between FSSBsm and WTFC $(\mathrm{r}(96)=-.12, p>.05)$ was, while in the expected direction, not significant, which precludes support for hypothesis $1 \mathrm{~d}$.

Discrepancies. Before conducting the polynomial regression, it is important to determine if there are indeed discrepancies present that might account for variance in the dependent variable. Table 2 depicts the percentage of the sample recorded as discrepant values (42\%), which supports the logical basis for conducting the subsequent analyses.

Polynomial Regression. Edwards (1994) describes the procedures for conducting polynomial regression which have been well-adopted by the SOA literature. The procedure requires first, determining the coefficients which satisfy the following regression equation:

$$
\mathrm{Z}=b_{0}+b_{1} X+b_{2} Y+b_{3} X^{2}+b 4 X Y+b_{5} Y^{2}+b_{6} Y^{2}+e
$$

$\mathrm{Z}$ is the dependent variable (e.g. WTFE), $X$ is Predictor 1 (self; FSSBsu) and $Y$ is Predictor 2 (other; FSSBsm). As such, each outcome variable is regressed on both of the predictor variables $(X$ and $Y$ ), the interaction between the two predictor variables $(X Y)$ and the squared terms for each of the two predictors as well $\left(X^{2}\right.$ and $\left.Y^{2}\right)$. Then, since these data can be depicted in three dimensions $(X, Y \& \mathrm{Z})$, a surface response analysis can determine if there are significant differences between supervisors who exhibit varying levels of SOA (Edwards, 1994).

WTFC, WTFE, OC and JS were all regressed onto FSSBsu and FSSBsm and the associated higher order terms consistent with the equation outlined above. Polynomial equation 
coefficients for each of the dependent variables are depicted in Table 3. Direct interpretation of the regression is not warranted in the SOA paradigm because it is the three-dimensional pattern resulting from the equation that we interpret and test for significance, the regression merely provides the requisite coefficients for the polynomial equation. Furthermore, interpreting the surface response makes sense only if the dependent variable models represent a significant proportion of the variance in the dependent variable. The regression models for $\mathbf{J C}, R^{2}=.22$, $F(5,90)=5.00, p<.001$, and $\mathbf{O C}, R^{2}=.24, F(5,90)=5.62, p<.001$, both captured a significant proportion of variance which justified further analyses. However, the regression models for WTFC, $R^{2}=.03, F(5,90)=.57, p>.05$, and WTFE, $R^{2}=.10, F(5,90)=2.00, p>.05$, did not capture a significant proportion of variance which precludes the surface response analysis, which means that the data do not support hypothesis $2 \mathrm{c}-\mathrm{d}$.

Surface Response Analysis. This portion of the analyses is concerned with testing the significance of the slopes representing certain "lines" on the polynomial surface pattern. For example, the line of "agreement," where $\mathrm{X}=\mathrm{Y}$, begins at $(-2,-2)$ and travels to the point $(2,2)$, with values of Z (e.g. JC) depicted as a product of equal values of X (FSSBsu) and Y (FSSBsm). Testing the significance of the slope of this "agreement" line answers the question, "what happens to $\mathrm{Z}$ when values of $\mathrm{X}$ and $\mathrm{Y}$ are congruent?". The linear slope of the line of agreement is given by the equation $a_{1}=b_{1}+b_{2}$, where $b_{1}$ is the unstandardized beta coefficient for FSSBsu and $b_{2}$ is the unstandardized beta coefficient for FSSBsm. See Table 3 for these slope values. The linear slope was positive and significant for both $\mathbf{J S}\left(\mathrm{a}_{1}=2.82, p<.05\right)$ and $\mathbf{O C}\left(\mathrm{a}_{1}=3.23, p\right.$ $<.05$ ) indicating that as both values of FSSBsu and FSSBsm rise together in tandem that values of JS and OC rise as well. This finding confirms hypotheses $2 \mathrm{a}$ and $2 \mathrm{~b}$. However, both outcome variables also exhibited significant curvilinear slopes as well $\left(\mathbf{J S} ; \mathrm{a}_{2}=-1.07, p<.05, \mathbf{O C} ; \mathrm{a}_{2}=-\right.$ 
$1.09, p<.05)$ which means that values of JS and OC are at their lowest when congruent values of FSSBsu and FSSBsm are both low and both high. Despite this, the linear slopes were much larger than the curvilinear slopes suggesting that the linear effect is more influential for both variables. Indeed, mildly convex surface response patterns can be witnessed along the line of congruence $(\mathrm{X}=\mathrm{Y})$ in both figure $2(\mathrm{JS})$ and figure $3(\mathrm{OC})$.

Visually Interpreting the Graphs. Once significant slopes are established, one can take a look at the three-dimensional graphs to see what is happening visually. It is important to remember that both FSSB measures have been centered on zero so that interpretations of the various points in the graph take this into account; 0 represents a score of 3 on the scale. In figure 1, it is apparent that the highest values of $\mathrm{JC}$ are along the edge of the graph where the highest values of FSSBsm lie, and which correspond with moderate values for FSSBsu. The same, but more pronounced, effect can be seen in the graph of the regression coefficients for OC, where the highest values of OC correspond with high values of FSSBsm and moderately high values of FSSBsu.

\section{Discussion}

This study contributes to the literature in a couple of important ways. First, the positive correlations of service-member reported FSSB with key job attitudes (JS, OC) is consistent with previous literature (Odle-Dusseau et al., 2016). However, this study extends this line of research to this unique sample (service-members in civilian workplaces) which has important implications for workplaces seeking to become employers of choice for service-members returning to the civilian workplace. Family support in the workplace appears important for this population. 
Next, the results of the surface response analysis demonstrated a significant linear relationship between supervisor-employee dyad congruence on FSSB and JS and OC. This finding points to the importance for supervisors to have an accurate assessment of the kinds of support they provide to their employees. Self-awareness has been promoted in the literature as a key supervisor and leadership ability (Tekleab, Sims, Yun, Tesluk, \& Cox, 2007), especially regarding transformational leadership. The findings in this study show that, for employed service-members, reported JS and OC are higher when a supervisor has similar perceptions of their own FSSB. When there is convergence of perceptions of FSSB, that is the "perceptual gap" is low, employees report higher levels of JS and OC.

However, there were unexpected results as well. First, the curvilinear relationship revealed that when both congruence and high scores were combined, ratings of JS and OC dropped a little bit. This curvilinear relationship was difficult to explain. It may be that very high scores of JS and OC are not explained by the FSSB construct. Perhaps more salient aspects of the job (pay, type of work, other aspects of management) explain variance in JS and OC at the higher end of the scale spectrum. Another unexpected finding is the relatively high scores on JS reported by service members who rated their supervisors low on FSSB, but whose supervisor rated themselves very highly. This is called the "overestimator" condition. Previous literature has shown that overestimators exhibit lower objective supervisor performance ratings (Atwater, Ostroff, Yammarino, \& Fleenor, 1998; Atwater, Waldman, Ostroff, Robie, \& Johnson, 2005). What might explain this finding is that supervisors who rate themselves highly, and accurately, on more general measures of supervisor support transport this self-assessment into the family support measure. Service members are better positioned to assess the differences between these two constructs (FSSB and general support) and so might experience high job satisfaction, high 
general supervisor support, but experience (and rate) their supervisors low on FSSB. It is a hypothesis worth testing.

Limitations. There were important limitations in this study. First, most of the supervisorservice member dyads existed in different organizations. This nesting effect was not taken into consideration in the analyses in this study. Organizational effects thus may be considered a confounding factor such that some of the variation in JS and OC might be accounted for by organizational factors outside the control of the supervisor. Future studies on these data should control for the effect that different organizations might have on the relationships tested in this study.

Another limitation is that only two lines on the surface response pattern were analyzed. The slope of any line on the surface response pattern can be analyzed for significance, but doing so is more complicated than analyzing the slopes of the lines of congruence $(\mathrm{X}=\mathrm{Y})$ and incongruence $(\mathrm{X} \neq \mathrm{Y})$ which were performed in this study. Looking at various other lines on the surface response pattern would enable the testing of a host of hypotheses not considered in this study. For example, it is visually apparent that high supervisor ratings corresponded with high levels of JC (see Figure 2), but this relationship may or may not be significant. A test of significance of this slope would require holding FSSBsm constant between -1 and -2 , and it can be done, but this analysis requires advanced understanding of surface response analysis methodology.

Another concern is the low reliability of the FSSBsu $(\alpha=.66)$ measure in this sample. The reliability for the FSSBsu measure before linking supervisors to service-members $(N=964$, $\alpha=.74)$ is much higher, indicating that the sample restriction due to linking had a detrimental effect on the reliability of the FSSBsu measure in this sample. Given that the same measure 
scored by service-members (FSSBsm; $\alpha=.92$ ) possess a much higher reliability, the reason for the low reliability must lie in the interpretation of each measure by the supervisors. This could be due to the nature of the scale which contains a single item for each dimension (creative management, role modeling, emotional support and instrumental support), and untrained supervisors might only rate themselves highly on a single dimension leading to low inter-item correlations when self-reporting. This issue should be more closely scrutinized in future iterations of research utilizing the FSSB construct measure from the supervisor's perspective.

\section{Conclusion}

Supervisor paradigms are shifting and so should best practices concerning which behaviors lead to the best employee outcomes. Empirical evidence of the importance of familysupportive supervisor behaviors expands continuously. This study reveals the importance of a supervisor's self-awareness regarding the issues pertaining to family life that employees may have. It also reveals the importance of dyad perspectives when considering the well-being of employees. 


\section{References}

Atwater, L. E., Ostroff, C., Yammarino, F. J., \& Fleenor, J. W. (1998). Self-other agreement: does it really matter? Personnel Psychology, 51(3), 577-598.

Atwater, L. E., Waldman, D., Ostroff, C., Robie, C., \& Johnson, K. M. (2005). Self-other agreement: Comparing its relationship with performance in the US and Europe. International Journal of Selection and Assessment, 13(1), 25-40.

Atwater, L. E., \& Yammarino, F. J. (1997). Self-other rating agreement: A review and model. Research in Personnel and Human Resources Management, 15, 121-174.

Bakker, A. B., Hakanen, J. J., Demerouti, E., \& Xanthopoulou, D. (2007). Job resources boost work engagement, particularly when job demands are high. Journal of Educational Psychology, 99(2), 274-284. https://doi.org/10.1037/0022-0663.99.2.274

Bakker, A. B., \& Schaufeli, W. B. (2008). Positive organizational behavior: Engaged employees in flourishing organizations. Journal of Organizational Behavior, 29(2), 147-154.

Bianchi, S. M., \& Milkie, M. A. (2010). Work and family research in the first decade of the $21 \mathrm{st}$ century. Journal of Marriage and Family, 72(3).

Carlson, D. S., Kacmar, K. M., Wayne, J. H., \& Grzywacz, J. G. (2006). Measuring the positive side of the work-family interface: Development and validation of a work-family enrichment scale. Journal of Vocational Behavior, 68(1), 131-164. https://doi.org/10.1016/j.jvb.2005.02.002

Černe, M., Dimovski, V., Marič, M., Penger, S., \& Škerlavaj, M. (2014). Congruence of leader self-perceptions and follower perceptions of authentic leadership: Understanding what authentic leadership is and how it enhances employees' job satisfaction. Australian Journal of Management, 39(3), 453-471. 
Day, D. V., Fleenor, J. W., Atwater, L. E., Sturm, R. E., \& McKee, R. A. (2014). Advances in leader and leadership development: A review of 25 years of research and theory. The Leadership Quarterly, 25(1), 63-82. https://doi.org/10.1016/j.leaqua.2013.11.004

Edwards, J. R. (1994). The study of congruence in organizational behavior research: Critique and a proposed alternative. Organizational Behavior and Human Decision Processes, 58, $51-$ 100.

Fleenor, J. W., McCauley, C. D., \& Brutus, S. (1996). Self-other rating agreement and leader effectiveness. Leadership Quarterly, 7(4), 487-506.

Fleenor, J. W., Smither, J. W., Atwater, L. E., Braddy, P. W., \& Sturm, R. E. (2010). Self-other rating agreement in leadership: A review. The Leadership Quarterly, 21(6), 1005-1034. https://doi.org/10.1016/j.leaqua.2010.10.006

Fox, S., Caspy, T., \& Reisler, A. (1994). Variables affecting leniency, halo and validity of selfappraisal. Journal of Occupational and Organizational Psychology, 67(1), 45-56.

Halverson, S. K., Tonidandel, S., Barlow, C., \& Dipboye, R. L. (2002). Self-other agreement on a 360-degree leadership evaluation. In 17th Annual Conference of the Society for Industrial and Organizational Psychology, Toronto, Canada. Retrieved from http://www.academia.edu/download/44957090/halverson_others2002.pdf

Hammer, L. B., Kossek, E. E., Yragui, N. L., Bodner, T. E., \& Hanson, G. C. (2009). Development and validation of a multidimensional measure of family supportive supervisor behaviors (FSSB). Journal of Management, 35(4), 837-856. https://doi.org/10.1177/0149206308328510

Hammer, Leslie B., Ernst Kossek, E., Bodner, T., \& Crain, T. (2013). Measurement development and validation of the Family Supportive Supervisor Behavior Short-Form (FSSB-SF). 
Journal of Occupational Health Psychology, 18(3), 285-296.

https://doi.org/10.1037/a0032612

Hammer, Leslie B., Kossek, E. E., Anger, W. K., Bodner, T., \& Zimmerman, K. L. (2011).

Clarifying work-family intervention processes: The roles of work-family conflict and family-supportive supervisor behaviors. Journal of Applied Psychology, 96(1), 134-150. https://doi.org/10.1037/a0020927

Hammer, Leslie B., Kossek, E. E., Bodner, T., \& Crain, T. (2013). Measurement development and validation of the family-supportive supervisor behavior short-form (FSSB-SF). Journal of Occupational Health Psychology, 18(3), 285-296. https://doi.org/10.1037/a0032612

Harris, M. M., \& Schaubroeck, J. (1988). A meta-analysis of self-supervisor, self-peer, and peersupervisor ratings. Personnel Psychology, 41, 43.

Matos, K., \& Galinsky, E. (2014). 2014 National Study of Employers (Families and Work Institute). SHRM.

Matthews, R. A., Kath, L. M., \& Barnes-Farrell, J. L. (2010). A short, valid, predictive measure of work-family conflict: Item selection and scale validation. Journal of Occupational Health Psychology, 15(1), 75-90. https://doi.org/10.1037/a0017443

Matthews, R. A., Mills, M. J., Trout, R. C., \& English, L. (2014). Family-supportive supervisor behaviors, work engagement, and subjective well-being: A contextually dependent mediated process. Journal of Occupational Health Psychology, 19(2), 168-181. https://doi.org/10.1037/a0036012 
Meyer, J. P., Allen, N. J., \& Smith, C. A. (1993). Commitment to organizations and occupations: Extension and test of a three-component conceptualization. Journal of Applied Psychology, 78(4), 538-551.

NPR, Robert W. Johnson Foundation, Harvard School of Public Health. (2016). The Workplace and Health.

Odle-Dusseau, H. N., Hammer, L. B., Crain, T. L., \& Bodner, T. E. (2016). The influence of family-supportive supervisor training on employee job performance and attitudes: An organizational work-family intervention. Journal of Occupational Health Psychology, 21(3), 296-308. https://doi.org/10.1037/a0039961

Seashore, S. E., Lawler, E. E., Mirvis, P. H., \& Cammann, C. (Eds.). (1983). Assessing organizational change: A guide to methods, measures, and practices. New York: WileyInterscience.

Szell, S., \& Henderson, R. (1997). The impact of self-supervisor/subordinate performance rating agreement on subordinates' job satisfaction and organisational commitment. Journal of Applied Social Behavior, 3, 25-37.

Tekleab, A. G., Sims, H. P., Yun, S., Tesluk, P. E., \& Cox, J. (2007). Are We On the Same Page? Effects of Self-Awareness of Empowering and Transformational Leadership. Journal of Leadership \& Organizational Studies, 14(3), 185-201. https://doi.org/10.1177/1071791907311069

Tsui, A. S., \& Ohlott, P. (1988). Multiple assessment of managerial effectiveness: Interrater agreement and consensus in effectiveness models. Personnel Psychology, 41(4), 779803. 
Table 1

Means, Standard Deviations, Alphas and Correlations for FSSBsu/sm, Job Sat., Org. Comm., WTFC and WTFE

\begin{tabular}{lcccccccc}
\hline & & & & \multicolumn{5}{c}{ Correlations } \\
\cline { 6 - 8 } & $M$ & $S D$ & Alpha & 1. & 2. & 3. & 4. & 5. \\
\hline 1. FSSBsu & 4.23 & .44 & .66 & - & & & & \\
2. FSSBsm & 3.89 & .84 & .92 & -.02 & - & & & \\
3. JS & 4.05 & .83 & .89 & -.02 & $.30 *$ & - & & \\
4. OC & 3.37 & 1.02 & .94 & .01 & $.38^{*}$ & $.64 *$ & - & \\
5. WTFC & 2.44 & .90 & .74 & .02 & -.12 & $-.32^{*}$ & -.20 & - \\
6. WTFE & 3.17 & .99 & .91 & -.01 & $.23 *$ & $.59 *$ & $.66^{*}$ & $-.38^{*}$ \\
\hline
\end{tabular}

Notes. $N=96 * p<.01$

Table 2

Frequencies of FSSBsu over/under estimating and in-agreement with FSSBsm

\begin{tabular}{lccc}
\hline Agreement groups & Proportion & Mean FSSBsu & Mean FSSBsm \\
\hline FSSBsu higher than FSSBsm & .27 & 4.56 & 3.08 \\
In agreement & .58 & 4.21 & 4.08 \\
FSSBsu lower than FSSBsm & .15 & 3.75 & 4.70 \\
\hline
\end{tabular}

Note: $N=96$ 
Table 3

Polynomial Regression models for dependent variables JC, OC, WTFC and WTFE

\begin{tabular}{lcccc}
\hline & JS & OC & WTFC & WTFE \\
\cline { 2 - 5 } & $b($ s.e. $)$ & $b($ s.e. $)$ & $b($ s.e. $)$ & $b($ s.e. $)$ \\
\hline Constant & $2.37^{*}(.69)$ & $1.29 *(.84)$ & $3.30^{*}(. .83)$ & $2.27 *(.88)$ \\
FSSBsu (X) & $1.51(1.02)$ & $1.92(1.23)$ & $-1.10(1.22)$ & $.49(1.29)$ \\
FSSB sm (Y) & $1.32^{*}(.34)$ & $1.30 *(.41)$ & $-.45(.40)$ & $.93 *(.43)$ \\
FSSBsu ${ }^{2}\left(\mathrm{X}^{2}\right)$ & $-.30(.37)$ & $-.47(.45)$ & $.35(.44)$ & $-.00(.47)$ \\
FSSBsu*FSSBsm $(\mathrm{XY})$ & $-.75^{*}(.21)$ & $-.68^{*}(.25)$ & $.17(.25)$ & $-.51(.26)$ \\
FSSBsm ${ }^{2}\left(\mathrm{Y}^{2}\right)$ & $-.02(.02)$ & $.07(.11)$ & $.08(.10)$ & $.01(.11)$ \\
$R$ & .47 & .49 & .18 & .32 \\
$R^{2}$ & .22 & .24 & .03 & .10 \\
$F$ & $5.00^{*}$ & $5.62^{*}$ & .57 & 2.00 \\
$a_{1}$ & $2.82^{*}$ & $3.23^{*}$ & & \\
$a_{2}$ & $-1.07 *$ & $-1.09 *$ & & \\
$a_{3}$ & .19 & .62 & & \\
$a_{4}$ & .44 & .28 & & \\
\hline
\end{tabular}

Notes. ${ }^{*} p<.05$.



Figure 1. Proposed relationships between self and other-reported FSSB and organizational outcomes. 


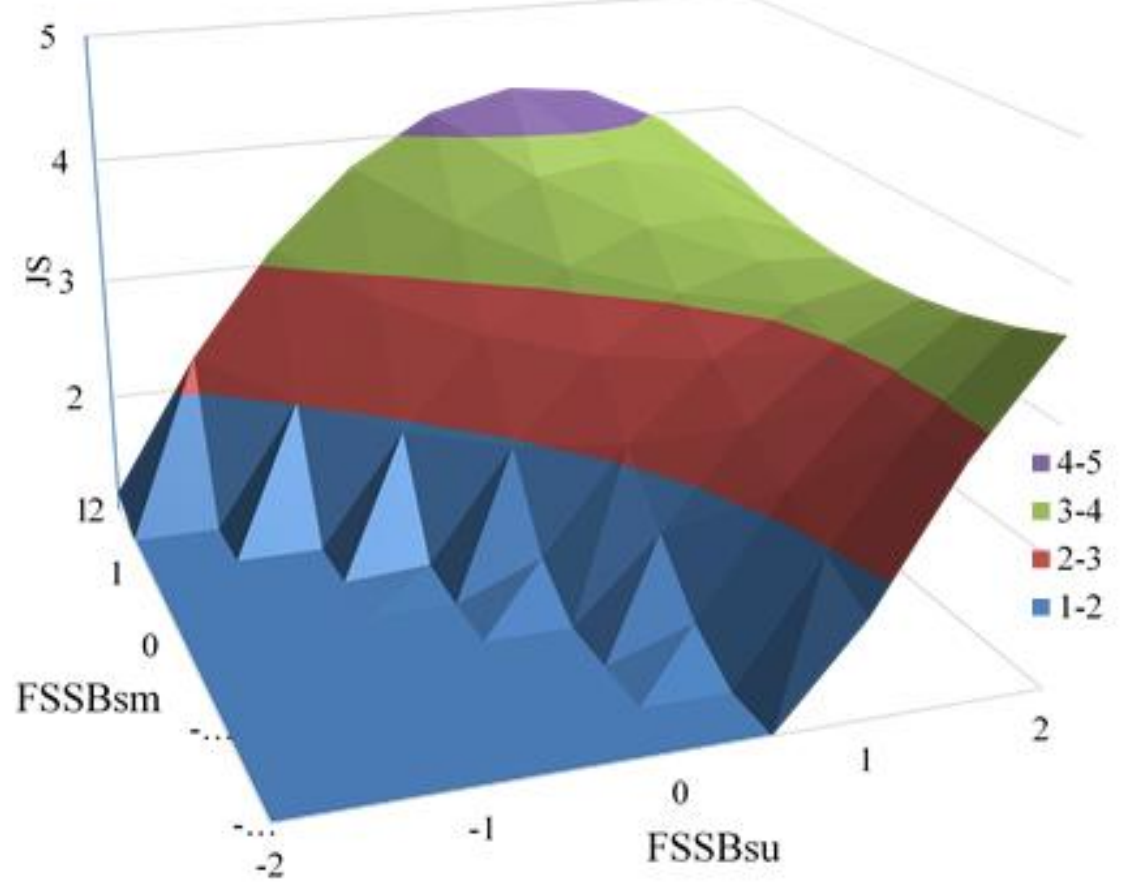

Figure 3. OC Surface Response Pattern

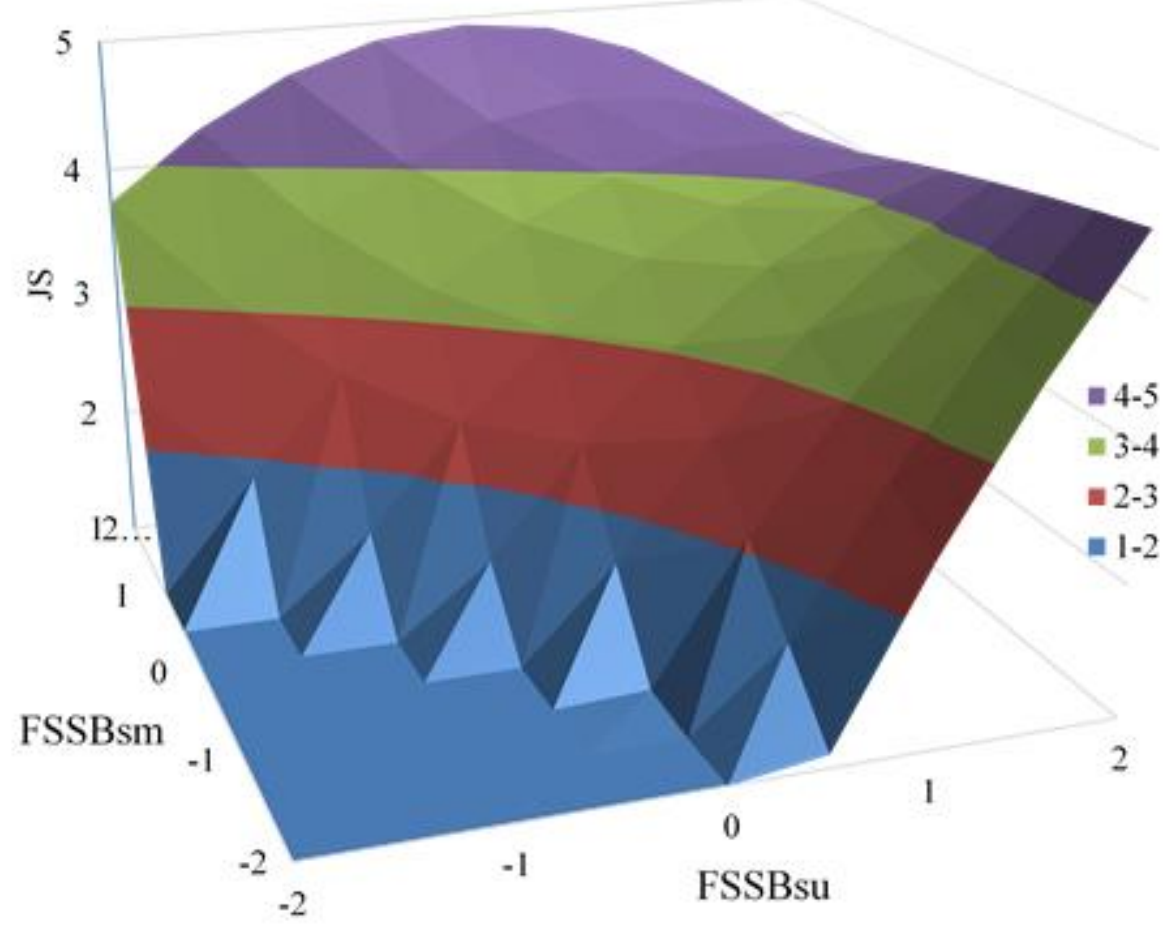

Figure 2. JS Surface Response Pattern 